\title{
Atypical histological abnormalities in an adult patient with nephronophthisis harboring NPHP1 deletion: a case report
}

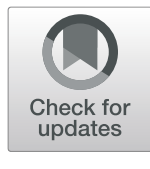

Maiko Akira' ${ }^{1}$ Hitoshi Suzuki ${ }^{1 *}$ D, Arisa Ikeda ${ }^{1}$, Masako Iwasaki ${ }^{1}$, Daisuke Honda ${ }^{1}$, Hisatsugu Takahara', Hisaki Rinno ${ }^{1}$, Shigeki Tomita ${ }^{2}$ and Yusuke Suzuki ${ }^{3}$

\begin{abstract}
Background: Nephronophthisis (NPHP) is a chronic tubular interstitial disorder that exhibits an autosomal recessive genetic form and causes progressive renal failure in children. Patients with NPHP rarely show urinary abnormalities, edema, or hypertension. Thus, NPHP is often detected only when renal failure becomes advanced. NPHP can be divided into three types based on the age of end-stage renal failure, i.e., infant type (approximately 5 years old), juvenile type (approximately 13-14 years old), and adolescent type (approximately 19 years old). Here, we report a case of NPHP diagnosed by genetic analysis at 26 years of age with atypical histological abnormalities.

Case presentation: A 26-year-old woman showed no growth disorders or urinary abnormalities in annual school physical examinations. However, at a check-up at 26 years old, she exhibited renal dysfunction (eGFR $26 \mathrm{~mL} / \mathrm{min} /$ $1.73 \mathrm{~m}^{2}$ ). Urine tests indicated low specific gravity of urine, but not proteinuria or microscopic hematuria. Urinary $\beta 2$-microglobulin was high $(805 \mu \mathrm{g} / \mathrm{L})$, and renal biopsy was performed for definitive diagnosis. Histological findings showed no significant findings in glomeruli. However, moderate fibrosis was observed in the interstitial area, and moderate atrophy was observed in the tubules. There were no significant findings in immunofluorescence analysis, and no electron dense deposits were detected by electron microscopy. Although cyst-like expansion of the tubules was unclear, tubular atrophy was dominantly found in the distal tubule by cytokeratin 7 staining. Genetic analysis of the NPHP1 gene showed complete deletion of this gene, leading to a definitive diagnosis of NPHP.

Conclusions: NPHP is not merely a pediatric disease and is relatively high incidence in patients with adult onset end-stage of renal disease. In this case, typical histological abnormalities, such as cyst-like expansion of the tubular lesion, were not observed, and diagnosis was achieved by genetic analysis of the NPHP1 gene, which is responsible for the onset of NPHP. In patients with renal failure with tubular interstitial disease dominantly in the distal tubules, it is necessary to discriminate NPHP, even in adult cases.
\end{abstract}

Keywords: Nephronophthisis, Distal tubule, Renal biopsy, End-stage renal failure

\footnotetext{
* Correspondence: shitoshi@juntendo.ac.jp

'Department of Nephrology, Juntendo University Urayasu Hospital, 2-1-1

Tomioka, Urayasu-shi, Chiba 279-0021, Japan

Full list of author information is available at the end of the article
}

\section{$\triangle B M C$}

(c) The Author(s). 2021 Open Access This article is licensed under a Creative Commons Attribution 4.0 International License, which permits use, sharing, adaptation, distribution and reproduction in any medium or format, as long as you give appropriate credit to the original author(s) and the source, provide a link to the Creative Commons licence, and indicate if changes were made. The images or other third party material in this article are included in the article's Creative Commons licence, unless indicated otherwise in a credit line to the material. If material is not included in the article's Creative Commons licence and your intended use is not permitted by statutory regulation or exceeds the permitted use, you will need to obtain permission directly from the copyright holder. To view a copy of this licence, visit http://creativecommons.org/licenses/by/4.0/ The Creative Commons Public Domain Dedication waiver (http://creativecommons.org/publicdomain/zero/1.0/) applies to the data made available in this article, unless otherwise stated in a credit line to the data. 


\section{Background}

Nephronophthisis (NPHP) is a chronic tubular interstitial injuries and is the most common genetic causes of renal failure in children and young adults [1]. The estimated incidence of NPHP is 1:50,000 to $1: 70,000[2,3]$, and account for approximately 10 to $15 \%$ of end-stage of renal disease (ESRD). Clinical features of NPHP are usually not specific, thus common features of chronic kidney disease (CKD), such as, urinary abnormalities, edema, and hypertension are rarely observed in patients with NPHP. Impairment ability to concentrate urine and retain body fluid induce polyuria, polydipsia, and decreased maximum urine concentration. Several patients with NPHP show extrarenal abnormalities, such as cerebellar ataxia, liver fibrosis, situs inversus, abnormal skeleton and facial features, Senior-Loken syndrome, Cogan syndrome and Joubert syndrome $[4,5]$.

NPHP is divided into three types based on the onset of ESRD, viz., infant type (approximately 5 years old), juvenile type (approximately 13-14 years old), and adolescent type (approximately 19 years old) [6]. It is not easy to diagnose as NPHP because of lack of specific clinical symptom. Thus, many of patients with NPHP progresses to ESRD in childhood or early adolescence. The diagnosis of NPHP is usually made by genetic analysis, as the findings in renal biopsy are not specific. The histopathology of NPHP is characterized by tubulointerstitial abnormalities, such as tubular atrophy, thickening or thinning of the tubular membrane, interstitial fibrosis and inflammation. However, those pathological phenotypes are not disease specific. Therefore, it is important to perform genetic analysis in suspected NPHP patients. Although NPHP has genetic heterogeneity, the most common NPHP mutation is a homozygous deletion of NPHP1, which is identified in $20 \%$ of patients with NPHP harboring NPHP gene mutations [7, 8]. Overall, a greater consideration of the diagnosis of NPHP is necessary to prevent expedited decline of renal function.

In the current report, we describe a case of NPHP diagnosed by genetic analysis at 26 years of age in a patient with atypical histological abnormalities.

\section{Case presentation}

The patient was a 26-year-old Japanese woman who showed no growth disorders or urinary abnormalities at school check-ups. However, during a medical check-up at 26 years of age, she showed renal dysfunction (serum creatinine $2.2 \mathrm{mg} / \mathrm{dL}$ ). The estimated glomerular filtration rate (eGFR) was $26 \mathrm{~mL} / \mathrm{min} / 1.73 \mathrm{~m}^{2}$, and urine tests indicated low specific gravity of urine (1.004); however, proteinuria and microscopic hematuria were not detected. Urinary $\beta 2$-microglobulin $(\beta 2-\mathrm{MG})$ was high $(805 \mu \mathrm{g} / \mathrm{L}$; Table 1). Analysis of her family history revealed that her father had chronic myelogenous leukemia and her mother had Sjogren's syndrome and renal dysfunction. At the time of renal biopsy, the patient's height, weight, and blood pressure were $155.6 \mathrm{~cm}, 51.4 \mathrm{~kg}$, and $122 / 91 \mathrm{mmHg}$, respectively. Physical examination findings were normal. An abdominal computed tomography scan revealed that both kidneys were normal in size. We performed a percutaneous renal biopsy for definitive diagnosis.

Histological findings showed global sclerotic lesions in approximately half of glomeruli (Fig. 1a). Moderate fibrosis was observed in the interstitial area, and moderate atrophy was observed in the tubules. Irregular splitting of the tubular basement membrane (ISTBM) [9] was also observed in some tubules (Fig. 1b). There were no significant findings in immunofluorescence analysis (Fig. 1c), and no electron dense deposits were detected by electron microscopy (Fig. 1d). Although cyst-like expansion of the tubules was unclear, tubular atrophy was

Table 1 Clinical examination at the renal biopsy

\begin{tabular}{|c|c|c|c|c|c|c|c|c|c|c|c|}
\hline \multicolumn{2}{|l|}{ Hematological } & \multicolumn{2}{|c|}{ Reference values } & \multicolumn{2}{|c|}{ Blood biochemistry } & \multicolumn{2}{|c|}{ Reference values } & \multicolumn{2}{|c|}{ Immunological test } & \multicolumn{2}{|c|}{ Reference values } \\
\hline WBC & 5700 & $3300 \sim 8600$ & $/ \mu l$ & TP & 7.0 & $6.6 \sim 8.1$ & $\mathrm{~g} / \mathrm{dl}$ & $\mathrm{CH} 50$ & 59 & $25.0 \sim 48.0$ & $U / \mu l$ \\
\hline $\mathrm{Hb}$ & 10.2 & $11.6 \sim 14.8$ & $\mathrm{~g} / \mathrm{dl}$ & Alb & 4.2 & $4.1 \sim 5.1$ & $\mathrm{~g} / \mathrm{dl}$ & C3 & 99 & $86 \sim 160$ & $\mathrm{mg} / \mathrm{dl}$ \\
\hline \multirow[t]{2}{*}{ Plt } & 28.2 & $15.8 \sim 34.8$ & $\times 10^{4} / \mu l$ & BUN & 19 & $8.0 \sim 20.0$ & $\mathrm{mg} / \mathrm{dl}$ & C4 & 24 & $17 \sim 45$ & $\mathrm{mg} / \mathrm{dl}$ \\
\hline & & & & Cre & 2.03 & $0.46 \sim 0.79$ & $\mathrm{mg} / \mathrm{dl}$ & $\lg G$ & 1216 & $870 \sim 1700$ & $\mathrm{mg} / \mathrm{dl}$ \\
\hline Urinalysis & & & & eGFR & 26 & $60 \sim$ & $\mathrm{mL} / \mathrm{min} / 1.73 \mathrm{~m}^{2}$ & $\lg A$ & 228 & $110 \sim 410$ & $\mathrm{mg} / \mathrm{dl}$ \\
\hline $\mathrm{pH}$ & 7.335 & $5.0 \sim 8.0$ & & Cystatin C & 2.05 & $0.56 \sim 0.87$ & $\mathrm{mg} / \mathrm{dl}$ & $\lg M$ & 152 & $33 \sim 190$ & $\mathrm{mg} / \mathrm{dl}$ \\
\hline Specific gravity & 1.004 & & & $\mathrm{Na}$ & 141 & $138 \sim 145$ & $\mathrm{mM} / \mathrm{l}$ & ANA & $<\times 40$ & $\sim 40$ & \\
\hline Protein & $<20$ & & $\mathrm{mg} / \mathrm{dl}$ & K & 4.1 & $3.6 \sim 4.8$ & $\mathrm{mM} / \mathrm{l}$ & anti SSA-Ab & 1.9 & $\sim 7$ & $\mathrm{U} / \mathrm{ml}$ \\
\hline $\mathrm{RBC}$ & $<1$ & & $/ \mathrm{HPF}$ & $\mathrm{Cl}$ & 107 & $101 \sim 108$ & $\mathrm{mM} / \mathrm{l}$ & anti SSB-Ab & $<1.0$ & $\sim 7$ & $\mathrm{U} / \mathrm{ml}$ \\
\hline WBC & $<1$ & & /HPF & $\mathrm{Ca}$ & 8.5 & $8.8 \sim 10.1$ & $\mathrm{mg} / \mathrm{dl}$ & MPO-ANCA & $<1.0$ & $\sim 3.5$ & $\mathrm{U} / \mathrm{ml}$ \\
\hline U-NAG & 1.4 & $0.7 \sim 11.2$ & $\mu \mathrm{g} / \mathrm{l}$ & CRP & $<0.1$ & $0.00 \sim 0.14$ & $\mathrm{mg} / \mathrm{dl}$ & PR3-ANCA & $<1.0$ & $\sim 3.5$ & $\mathrm{U} / \mathrm{ml}$ \\
\hline$U-\beta 2 M G$ & 805 & $\sim 230$ & $\mu \mathrm{g} / \mathrm{l}$ & $\mathrm{HbA1c}$ & 5.7 & $4.9 \sim 6.0$ & $\%$ & anti GMB-Ab & $<2.0$ & $\sim 3$ & $\mathrm{U} / \mathrm{ml}$ \\
\hline
\end{tabular}


(a)
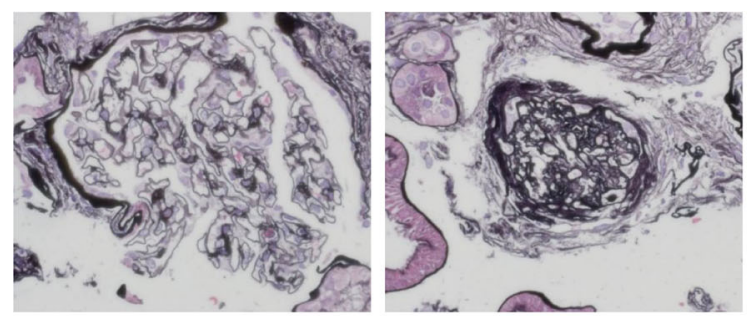

(b)
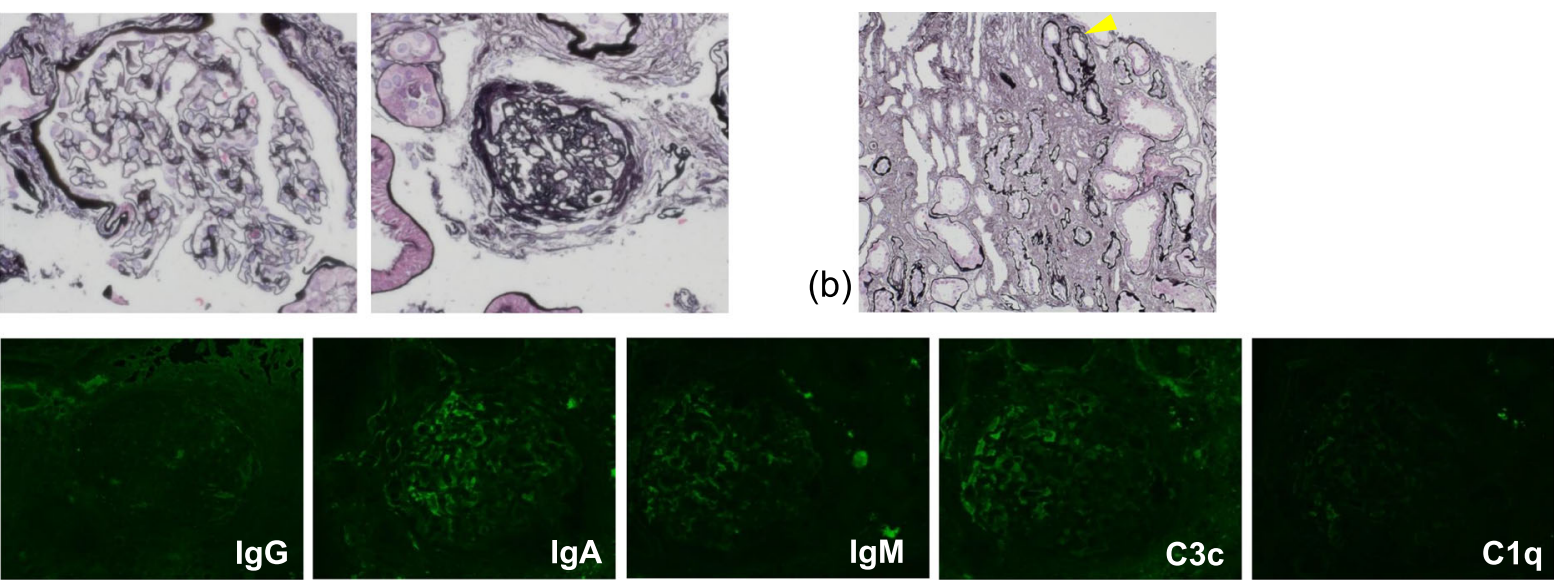

(c)

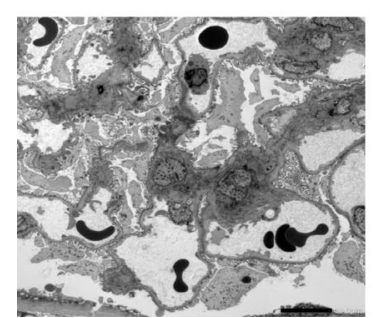

(e)
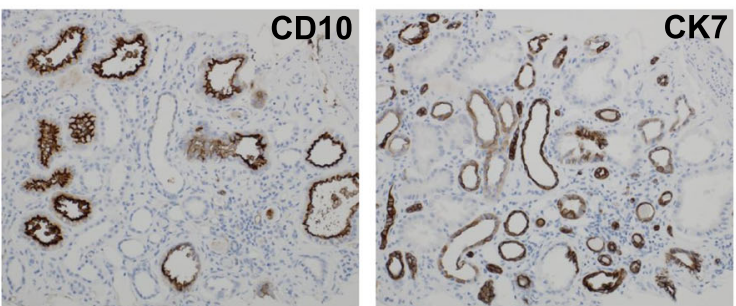

Fig. 1 Renal biopsy histopathology. a Light microscopic findings indicate global sclerosis in half of the glomeruli. However, the other glomeruli showed minor lesions (periodic acid-silver methenamine stain; original magnification, 200x). b Moderate fibrosis was observed in the interstitial area, and moderate atrophy was observed in the tubules (periodic acid-silver methenamine stain; original magnification, 100x). Irregular splitting TBM was also observed in some tubules (arrowhead). c There were no significant findings in immunofluorescence analysis. $\mathbf{d}$ No electron dense deposits were detected by electron microscopy. e Cyst-like expansion of the tubular was unclear. Tubular atrophy was dominantly found in the distal tubule by CK7 staining (original magnification, 100x)

dominantly found in the distal tubules by cytokeratin 7 (CK7) staining (Fig. 1e).

Next, we analyzed the NPHP1 gene, the most common gene responsible for NPHP. No exons of NPHP1 (1, 9, and 19) were amplified (Fig. 2a). Furthermore, multiplex ligation-dependent probe amplification analysis indicated complete deficiency of the NPHP1 gene (Fig. 2b). Based on these results, both alleles of NPHP1 were considered to be deleted in the current case, leading to a diagnosis of a total deletion of NPHP1.

(a)

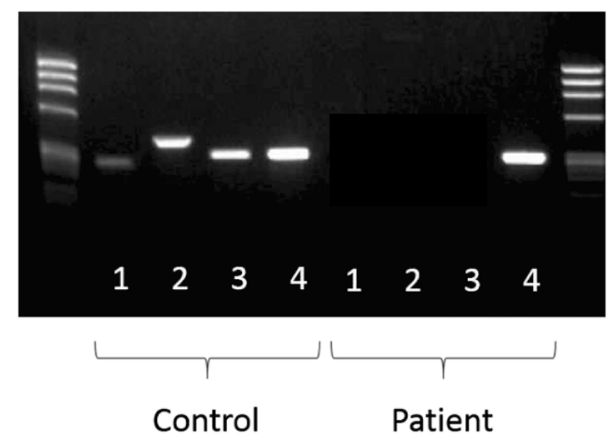

(b)

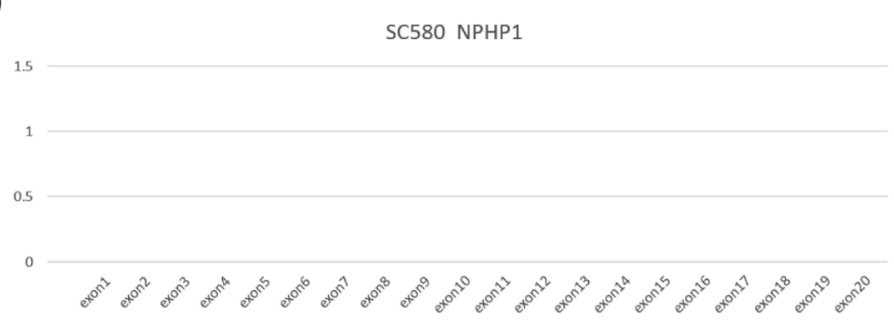

1: NPHP1 exon 1
2: NPHP1 exon 9
3: NPHP1 exon19
4: EYA1 exon5 (control)

Fig. 2 Genetic analysis of the NPHP1 gene. a No exons from NPHP1 were amplified. b Multiplex ligation-dependent probe amplification analysis indicated complete deficiency of the NPHP1 gene 


\section{Discussion and conclusion}

NPHP is the most common genetic cause of kidney failure in children and young adults $[8,10]$, with an estimated incidence of 1:50,000 [11, 12]. NPHP accounts for $6-10 \%$ of cases of kidney failure and $15 \%$ of renal transplants among children [13, 14]. NPHP has significant genetic heterogeneity, with biallelic pathogenic variants in 20 different genes identified as causative [15] with NPHP1 (20\%) being the most common gene [8, 16, 17]. Although NPHP is the most common genetic cause of chronic kidney disease (CKD) in children, its prevalence in the adult population is thought to be low. However, Snoek $\mathrm{R}$, et al. recently reported that the frequency of NPHP in adult onset ESRD is substantially higher than previous report [18]. Genome-wide association study using adult renal transplant recipients from several cohorts revealed median age of adult onset of ESRD was 30 , ranged from 18 to 61 years old, in patients with NPHP [18]. Thus, NPHP should be considered as a differential diagnosis in adult patients with unidentified ESRD. With no specific management available, treatment focuses on supportive and preventative strategies to preserve kidney function. However, a greater consideration of the diagnosis of NPHP in adult patients with kidney failure and progressive CKD is required to allow informed prognosis, targeted screening of at-risk family members, and expedited preventative and management strategies of kidney function decline $[19,20]$.

The findings of this case report emphasize the importance of CD10 and CK7 staining in cases in which the cause of renal dysfunction is unclear. Irregular splitting TBM in tubules is an important finding suggesting autosomal dominant tubulointerstitial kidney disease [9]. In patients with renal failure with tubular interstitial disease dominantly in the distal tubule, it is necessary to discriminate NPHP, even in adult patients. Moreover, it is important to perform genetic testing to obtain a definitive diagnosis, which will enable appropriate genetic counseling and treatment. Further studies are necessary to clarify the mechanisms leading to wide variance in age of disease onset.

In summary, NPHP often progresses to ESRD at an average age of 13-14 years old. However, NPHP is not merely a pediatric disease and is relatively high incidence in patients with adult onset ESRD. Even in cases without typical histological abnormalities, such as cyst-like expansion of tubular lesions, differential diagnosis of NPHP is critical. Thus, wider application of genetic testing is recommended to patients with unidentified ESRD.

\section{Abbreviations}

NPHP: Nephronophthisis; ESRD: End-stage of renal disease; eGFR: Estimated glomerular filtration rate; $\beta 2-M G$ : $\beta 2$-microglobulin; TBM: Tubular basement membrane; CK7: Cytokeratin 7

\section{Acknowledgements}

We would like to express our appreciation to the patient for her permission to publish this case. We also thank Drs. Naoya Morisada and Kazumoto lijima (Department of Pediatrics, Kobe Graduate School of Medicine) for their voluntary genetic analysis.

\section{Authors' contributions}

MA and HS reviewed the patient's clinical data and wrote the initial draft of the manuscript. Al, MI, DH, HT, and HR assisted in the preparation of the manuscript and contributed to data collection and interpretation. ST analyzed the pathology of the renal biopsy. HS and YS conceived of the case report; carried out analyses of the patient's clinical course, outcomes, and interpretation of the findings; and provided critical review comments for the manuscript. The authors read and approved the final manuscript.

\section{Funding}

This study was supported in part by a Grant-in-Aid for Intractable Renal Diseases Research, Research on rare and intractable diseases, Health and Labour Sciences Research Grants from the Ministry of Health, Labour and Welfare of Japan. The funder supported costs for English proofreading and the fees upon acceptance for publication.

Availability of data and materials

The datasets used in the current study are available from the corresponding author on reasonable request.

\section{Declarations}

Ethics approval and consent to participate

Not applicable.

Consent for publication

Written informed consent was obtained from the patient for the publication of this case report and any accompanying images.

\section{Competing interests}

The authors declare that they have no competing interests.

\section{Author details}

${ }^{1}$ Department of Nephrology, Juntendo University Urayasu Hospital, 2-1-1 Tomioka, Urayasu-shi, Chiba 279-0021, Japan. ²Department of Pathology, Juntendo University Urayasu Hospital, Chiba, Japan. ${ }^{3}$ Department of Nephrology, Juntendo University Faculty of Medicine, Tokyo, Japan.

Received: 16 February 2021 Accepted: 1 July 2021

Published online: 10 July 2021

References

1. Wolf MT. Nephronophthisis and related syndromes. Curr Opin Pediatr. 2015; 7:201-11.

2. Potter DE, et al. Jr treatment of end-stage renal disease in children: a 15year experience. Kidney Int. 1980;18:103-9.

3. Ala-Mello S, et al. Molecular studies in Finnish patients with familial juvenile nephronophthisis exclude a founder effect and support a common mutation causing mechanism. J Med Genet. 1998;35:279-83.

4. Tsang SH, Aycinena ARP, Sharma T. Ciliopathy: senior-Løken syndrome. Adv Exp Med Biol. 2018;1085:175-8.

5. Wang SF, et al. Review of ocular manifestations of joubert syndrome. Genes (Basel). 2018;9:605

6. Krishnan R, Eley L, Sayer JA. Urinary concentration defects and mechanisms underlying nephronophthisis. Kidney Blood Press Res. 2008;31:152-62.

7. Hildebrandt F, et al. A novel gene encoding an $\mathrm{SH} 3$ domain protein is mutated in nephronophthisis type 1. Nat Genet. 1997;17:149-53.

8. Sugimoto K, et al. Clinical and genetic characteristics of Japanese nephronophthisis patients. Clin Exp Nephrol. 2016;20:637-49.

9. Kitamura H. Gene mutation and morphological changes of MCKD and ADTK D. Japanese Soc Nephrol. 2018;60:1239-43.

10. Mollet $\mathrm{G}$, et al. The gene mutated in juvenile nephronophthisis type 4 encodes a novel protein that interacts with nephrocystin. Nat Genet. 2002; 32:300-5. 
11. Konig J, et al. Phenotypic spectrum of children with nephronophthisis and related ciliopathies. Clin J Am Soc Nephrol. 2017;12:1974-83.

12. Hildebrandt F, Zhou W. Nephronophthisis-associated ciliopathies. J Am Soc Nephrol. 2007;18:1855-71.

13. Mistry K, et al. Novel mutations in NPHP4 in a consanguineous family with histological findings of focal segmental glomerulosclerosis. Am J Kidney Dis. 2007;50:855-64.

14. Hoefele J, et al. Mutational analysis of the NPHP4 gene in 250 patients with nephronophthisis. Hum Mutat. 2005;25:411.

15. Hildebrandt F, Attanasio M, Otto E. Nephronophthisis: disease mechanisms of a ciliopathy. J Am Soc Nephrol. 2009;20:23-35.

16. Srivastava S, et al. Many genes-one disease? Genetics of nephronophthisis (NPHP) and NPHP-associated disorders. Front Pediatr. 2017;5:287.

17. Caridi G, et al. Clinical and molecular heterogeneity of juvenile nephronophthisis in Italy: insights from molecular screening. Am J Kidney Dis. 2000;35:44-51.

18. Snoek R, et al. NPHP1 (nephrocystin-1) gene deletions cause adult-onset ESRD. J Am Soc Nephrol. 2018;29:1772-9.

19. Bakkaloglu SA, et al. Diverse phenotypic expression of NPHP4 mutations in four siblings. Turk J Pediatr. 2014;56:423-6.

20. Srivastava S, Sayer JA. Nephronophthisis. J Pediatr Genet. 2014;3:103-14.

\section{Publisher's Note}

Springer Nature remains neutral with regard to jurisdictional claims in published maps and institutional affiliations.

Ready to submit your research? Choose BMC and benefit from:

- fast, convenient online submission

- thorough peer review by experienced researchers in your field

- rapid publication on acceptance

- support for research data, including large and complex data types

- gold Open Access which fosters wider collaboration and increased citations

- maximum visibility for your research: over $100 \mathrm{M}$ website views per year

At $\mathrm{BMC}$, research is always in progress.

Learn more biomedcentral.com/submissions 